\title{
Imaginal experience and attenuation of the galvanic skin response to shock
}

\author{
R. M. YAREMKO \\ San Diego State University, San Diego, California 92182 \\ and \\ MARK C. BUTLER \\ Institute of Behavioral Research \\ Texas Christian University, Fort Worth, Texas 76129
}

\begin{abstract}
The effect of imagining shocks or other events on later responding to real shocks was studied. Three groups of college subjects imagined either 10 lights, 10 shocks, or nothing, while a fourth group received 10 real shocks: All subjects then received 10 real shocks. Those subjects who imagined the shocks demonstrated fewer trials to an attenuation criterion than subjects imagining a light or receiving neutral stimulation. The results suggest that imagining shock facilitated attenuation of the response to real shocks. Relationships to previous studies were discussed.
\end{abstract}

Yaremko, Glanville, and Leckart (1972) reported the effects of repeated instructions to imagine a simple, neutral stimulus or later habituation of the GSR component of the orienting reflex. (OR) to the real event. They found that subjects given one $500-\mathrm{Hz}$ tone, then told to imagine the tone periodically, showed greater habituation to a series of real tones than subjects instructed to imagine a control stimulus (light) or subjects who imagined nothing. Also, no differences were found between subjects who imagined tones and those who experienced an equivalent number of real tones prior to the test series. These results suggest that imaginal experience with a neutral stimulus reduces the OR to that stimulus. Further, Yaremko and Werner (1974) demonstrated that repeatedly imagining a paired CS-US (tone-shock) event led to reliably greater resistance to extinction of classical conditioning than did imagining unpaired stimuli. These findings demonstrate the importance of imaginal stimulus experience as an instructional manipulation in studies of autonomic nervous system habituation and conditioning.

This study examined the effects of imaginal experience with an unconditioned aversive stimulus (shock). Even though shocks are classified as

Based on an MA thesis by the second author. Portions of this paper were presented at the Psychonomic Society Convention, November, 21-23, 1974, Boston, Massachusetts. This research was supported in part by San Diego State University Foundation Grant 221-212-979 to the first author. Address reprint requests to R. M. Yaremko, Department of Psychology, San Diego State University, San Diego, California 92182. nonhabituable stimuli (capable of evoking defensive reflexes) according to extant theorizing (e.g., Sokolov, 1963), it was assumed that such stimuli also initially evoke an (habituable) OR component by virture of stimulus novelty. Thus, it was expected that the effects of imagining a model shock would result in greater attenuation of the OR component of the response to real shocks than for subjects requested to imagine a control stimulus, or who imagine nothing at all.

\section{METHOD}

\section{Subjects and Apparatus}

Twenty-five male and 35 female introductory psychology students at San Diego State University were conscripted to partially satisfy a course requirement. All subjects knew the study involved electric shock when they volunteered.

Data were collected from the subject seated in a darkened IAC Model 401-A sound attenuated chamber containing a cushioned chair. The GSR was detected as a dc resistance change on the subject's left palm and forearm by zinc-zinc sulfate electrodes in Lucite cups filled with Redux electrode jelly. A Model 228 Applegate stimulator delivered a $2.5 \mathrm{~mA}$ shock for $.2 \mathrm{sec}$ through two zinc electrodes attached to the volar surface of the subject's right forearm. Responses were amplified and recorded by a Grass Model 5-D polygraph containing a Grass 5P-1 dc preamplifier. Paper speed was $1.5 \mathrm{~mm} / \mathrm{sec}$. A $2.5 \mathrm{~cm}$ in diam low intensity white light was located about $30 \mathrm{~cm}$ in front of the subject.

\section{Design and Procedure}

On arrival, each subject was randomly assigned to one of four preshock conditions: imagine light (IL), imagine shock (IS), real shock (RS), or neutral stimulation (NS), with the stipulation that each group had $n$ subjects before any group had $n+1$ subjects.

While the subjects' hands were cleaned with acetone and the electrodes attached, they were told informally that the 
experiment intended to study simple physiological responses to various stimuli. In the chamber they were cautioned to avoid excessive movement, relax, but remain alert. All subjects understood that they could terminate their participation at any time without penalty.

During Phase I of the study, each subject received a "model" shock and light, (3.0-sec duration for the light). The shock-light sequence was reversed for one half of the subjects in each group. This interstimulus interval was approximately $10 \mathrm{sec}$. In Phase II subjects received instructions tailored to the different conditions. Group RS was told that they would receive additional shocks. Group NS was told, at various times, that they were "doing fine," to control for the verbal stimulation given the remaining groups. Groups IL and IS were instructed that they would, at various times, be requested to "mentally reproduce" the sensation of the light or shock when they heard the word "imagine." These instructions were given through an intercom, and all subjects received 10 verbal commands (or shocks). In Phase III, all subjects received 10 real shocks. For all stimuli in Phases II and III, the intertrial interval varied between 30 and $70 \mathrm{sec}$, with a mean of $50 \mathrm{sec}$.

\section{RESULTS AND DISCUSSION}

Responses to shocks in Phase III were defined as the first GSR to occur within 1.5 and $4.0 \mathrm{sec}$ following stimulus onset. The response was transformed into log conductance units according to the formula: $\log$ (resistance base/resistance peak). Data were reduced in two ways. The more conventionally accepted measure (mean GSR amplitude) showed that Groups IL and NS were consistently more responsive than were Groups RS and IS, and that the latter two groups were nearly identical in responsiveness over the 10 shock trials in Phase III. ANOVA, however indicated that these differences were not reliable. A second index of responsiveness 'was designed to measure the number of trials to a criterion of $25 \%$ reduction of GSR amplitude from the first test shock trial. This was based on the assumption that GSRs to an aversive stimulus contain a small OR component when the stimulus is relatively novel, and the observation that diminution of GSR amplitudes was not nearly so great as is the case for habituation to neutral stimuli. Since Group RS had previous shock trials, and presumably had been habituated to shocks, this group was omitted from the analysis. Mean trials to criterion scores were: Group IS, 1.8; Group NS, 4.9; and Group IL, 5.0. ANOVA indicated that the differences among the remaining groups were significant, $F(2,42)=3.92, p<.05$. Duncan's multiple range test indicated that Group IS was significantly different $(p<.05)$ from the other two groups, while Groups NS and IL did not differ.
These results are reasonably consistent with the hypothesis that imaginal experience with an unconditioned aversive stimulus facilitates response attenuation when the real event is encountered later. That the present demonstration was somewhat weaker than our earlier findings may be due in part to the stimuli employed here. In the Yaremko et al. (1972) study, subjects imagined, then received, a series of neutral tones-highly habituable stimuli. As in the present study, we concluded that the imagery task helped form a primitive neuronal model (Sokolov, 1963) of the tone, and this model was then quickly refined by the real tone trials, resulting in more rapid OR habituation. The response to shock, however, contains a far smaller proportion of habituable OR than the response to tones, and thus, is more resistant to modification through imaginal experience. An alternative argument, that subjects may be less willing to imagine aversive events, is weakened by Yaremko and Werner's (1974) successful demonstration of classical conditioning through imagination.

As in the Yaremko et al. (1972) study, the fact that subjects who imagined the control stimulus were not different from subjects who imagined nothing rules out the explanation that control subjects were, by contrast, rendered more responsive from the contrary-to-fact expectancy developed by imagining lights. The results, then, lend additional support to the notion that the novelty component of any given stimulus can be reduced by instructing the subject to imagine the event. The evidence to date points strongly toward conceiving of this phenomenon in terms of the incremental growth of a neuronal model via repeated vicarious experience with the stimulus. However, the somewhat different view, that instructions to imagine constitute an implicit message regarding forthcoming events, and therefore create "general expectancies," certainly needs to be explored directly.

\section{REFERENCES}

Sokolov, E. N. Perception and the conditioned reflex. New York: Pergamon Press, 1963.

Yaremko, R. M., Glanville, B. B., \& Leckart, B. T. Imagery-mediated habituation of the orienting reflex. Psychonomic Science, 1972, 27, 204-206.

Yaremko, R. M., \& Werner, M. Cognitive conditioning: Imagined stimulus contiguity and the third interval conditional GSR. Pavlovian Journal of Biological Science, 1974, 9, 215-221.

(Received for publication December 18, 1974.) 